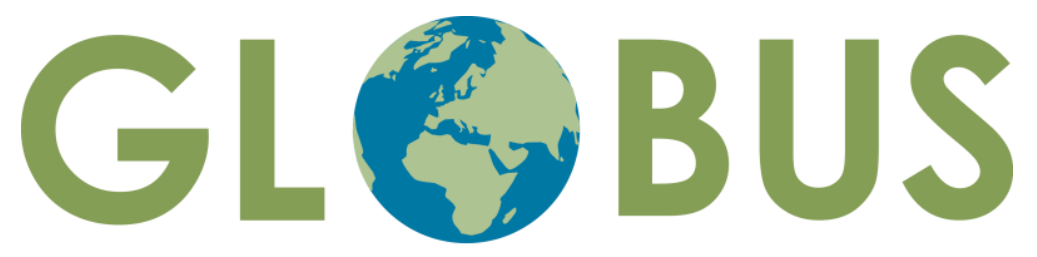

Reconsidering European Contributions to Global Justice

\title{
Global Gender Justice
}

\section{Distributive Justice or \\ Participatory Parity?}

Cathrine Holst

\section{GLOBUS Research Papers}

1/2019 - March 2019 
Cathrine Holst

Global Gender Justice: Distributive Justice or Participatory Parity?

GLOBUS Research Paper 1/2019

March 2019

(C) Cathrine Holst

GLOBUS Research Papers (online) | ISSN: 2535-2504

http://www.globus.uio.no/publications/globus-research-papers/

Cathrine Holst is Researcher at ARENA Centre for European Studies and Professor at Department of Sociology and Human Geography, University of Oslo

Reconsidering European Contributions to Global Justice (GLOBUS) is a research project that critically examines the EU's contribution to global justice.

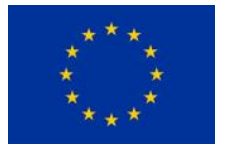

Funded by the European Union's Horizon 2020 programme. This work is the sole responsibility of the author. It does not reflect the opinion of the EU. The Research Executive Agency is not responsible for any use that may be made of the information it contains.

\footnotetext{
(1) www.globus.uio.no

E Twitter: @globus_h2020

f Facebook: @globus.h2020
}

Issued by:

ARENA Centre for European Studies

University of Oslo

P.O. Box 1143 Blindern

0318 Oslo, Norway

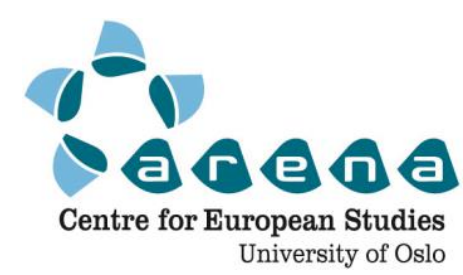

www.arena.uio.no 


\section{Abstract}

The paper compares two prominent approaches to global gender justice; Alison Jaggar's 'distributive' approach and Nancy Fraser's 'participatory' approach. It argues that both theories have contributed valuably to develop the feminist criticism of conventional justice theories, and to conceptualise and criticise the entanglement of global injustices and gender vulnerability. However, there are also considerable differences between the two theorists, in that Fraser makes a break with the distributive paradigm' and puts the relationship between justice and democracy at the centre stage, whereas Jaggar formulates her justice notion in distributive terms, and leaves the more detailed relationship between justice and democracy largely unaddressed. The two theories are furthermore discussed and assessed in light of the GLOBUS framework and its conceptions of global political justice. It is argued that justice as non-domination plays a non-trivial, yet limited, role in both theorists' approaches. Justice as impartiality also prevails in both contributions, but whereas impartiality ideas are tempered in Fraser by her democratic approach and commitment to the mutual recognition conception, Jaggar's theory stands out as more limited and with a democratic deficit, from a GLOBUS perspective. However, a fair assessment must consider how GLOBUS is consciously tailored towards questions of political justice. The framework thus sets aside several of the central distributive issues that Jaggar primarily wants to address with her global gender justice theorising. A criticism of a possible democratic deficit in Jaggar's approach should also distinguish between the promotion of substantive and 'radical' ideas of democracy of the kind Fraser pursues, and a commitment to general democratic norms. Finally, the paper draws some lessons from the paper's discussions for both feminist theory and for GLOBUS.

\section{Keywords}

Democracy, feminist theory, gender, global justice, theories of justice

This paper was written as a part of the GLOBUS project, funded by the European Union's Horizon 2020 research and innovation programme under grant agreement no. 693609 (GLOBUS). 



\section{Introduction ${ }^{1}$}

Theories of global justice inquire into what justice requires beyond state borders. Theories of gender justice investigate what justice demands if we are to treat women and men with equal respect. Both theories of global justice and theories of gender justice have challenged and aptly changed our theorising on justice. Yet, until recently, these branches of theorising have moved along largely separate paths. Core questions of what global justice demands from a gender perspective, and what gender justice requires from a global perspective, have thus been left relatively unscrutinised.

However, there are exceptions to this trend, and the theories of justice developed by Alison Jaggar and Nancy Fraser are among the most noteworthy. Jaggar and Fraser are both central contemporary feminist theorists, and their writings tend to be of interest whenever questions of gender and justice are under scrutiny. Furthermore, both Jaggar and Fraser regard it as a core concern for both feminism and theorising on justice to better relate issues of gender justice and issues of global justice. However, despite this overlapping preoccupation, the two theorists seem to offer rather different approaches to global gender justice. Alison Jaggar (2009a: 2, see also Jaggar 2009b, 2013, 2014) elaborates a notion of global gender justice centred on questions of 'distributive justice'. Nancy Fraser (2013: 193, 159-173, see also Fraser and Honneth 2004), on the other hand, regards 'redistribution' as one of several 'preconditions' for ensuring proper justice, meaning 'parity of participation', or 'social arrangements that permit all to participate as peers in social life'.

This paper compares and assesses Jaggar's and Fraser's contributions utilising GLOBUS' global justice framework, and draws on this basis some lessons for theorising on global gender justice. The first part of the paper outlines some main features of Jaggar's 'distributive' approach and Fraser's 'participatory' approach, and provides an initial comparison. In the second part, the two contributions are discussed in relation to GLOBUS' three conceptions of global political justice: justice as non-domination, justice as impartiality, and justice as mutual recognition (Eriksen 2016, Sjursen 2017). It is argued that Fraser's theory comes close to a theory that integrates all three conceptions in the way that the GLOBUS framework recommends. Unsurprisingly, this theory is thus less haunted by the 'serious limitations' the framework contends are characteristic of theories of global justice based on only one of these three conceptions (Eriksen 2016: 4). Jaggar's theory, on the contrary, in part balances the three conceptions in a way that makes it more vulnerable to some of these 'limitations'; in part addresses questions that

\footnotetext{
${ }^{1}$ I am grateful for valuable comments on an earlier draft of this paper from Solveig Aamodt, Vera Sofie Borgen, Erik Oddvar Eriksen, Sigrid Jerpstad, Asimina Michailidou, and Helene Sjursen. Andreas Eriksen in particular has offered detailed and useful comments on a previous version, and I have tried to take some of his key concerns into consideration. Other points (that were no less well-targeted) must be left for another occasion due to the limited scope and specific aims of this paper. Thank you also to Johanne Døhlie Saltnes for numerous stimulating discussions on the GLOBUS framework, and what it does - and does not - imply.
} 
are less central to GLOBUS' approach since this approach focuses primarily on 'political and administrative structures', and not on 'the distribution of goods' (Eriksen 2016: 2). The third section of the paper discusses the severity of the mentioned limitations and seemingly limited relevance of Jaggar's theory. To what extent is a general problem for this theory that it in some central respects fall short of the GLOBUS framework's assessment standards and outside its scope? The final section sums up and highlights some implications both for feminist discussions and for our understanding of GLOBUS' intervention in justice discussions.

\section{Global Gender Justice: Two Approaches}

\section{Alison Jaggar: Global Gender Justice as Distributive Justice}

In her approach to global gender justice, Alison Jaggar takes as her point of departure an idea of 'distributive justice' 2 that 'addresses questions concerning the fair distribution of the benefits and burdens of participating in a cooperative enterprise' (Jaggar 2009a: 2). She goes on to list five types of questions that accounts of distributive justice typically try to answer - where, when, who, what, and how-questions:

1. 'Where?' asks what is the domain or sphere of life within which the moral demands of justice apply. 2. 'When?' asks what are the social circumstances within which the demands of justice have application. 3. 'Who?' asks which entities should be regarded as subjects of justice, meaning who or what are entitled to make justice claims deserving of moral consideration. 4. 'What?' asks which entities should be regarded as objects of justice, meaning which kinds or categories of things should be distributed in a just manner. 5. Finally, 'How?' asks which principles are the most morally appropriate for guiding the allocation of various objects to various subjects in various circumstances.

(Jaggar 2009a: 2).

In addition, there is always the sixth question of $w h y$ : Theories of distributive justice will also try to explain the reasons behind the answers given to the other five kinds of questions.

\footnotetext{
${ }^{2}$ Other ideas of justice that she sets aside ('although it should be noted' that also these justice ideas 'have gender dimensions and can be raised in global contexts'), are 'retributive justice' about the appropriate punishment of wrongdoers, and 'reparative justice' about how to rectify past wrongs (Jaggar 2009a: 2).
} 
On this background, Jaggar gives an outline of feminist contributions to theories of distributive justice - and the idea of gender justice that has evolved - in relation to this list of questions. The outline starts out with elaborating how feminist contributions draw on developments in Western political philosophy after World War II and its emphasis on liberty and equality for all. Jaggar mentions here the influence of John Rawls' $A$ Theory of Justice and his idea of justice as fairness, which emphasises 'the interdependence of liberty and equality' and how 'formal equality' must be combined with socio-economic redistribution to ensure 'substantive equality' (Jaggar 2009a: 4). Jaggar (2009a: 5-6) also recognises how critical theory of race and ethnicity has inspired feminist political philosophy, including the idea that groups, and not only individuals, can be the subjects of justice, and the idea that cultural recognition, and not only political rights and economic and social goods, can be the objects of justice.

However, feminist contributions on gender justice have also offered distinctive answers of its own, according to Jaggar. Firstly, to the question of what belongs within the domain of justice. Whereas political philosophy for centuries had regarded family life and intimate relations as part of a private sphere where justice claims do not apply, feminist theorists of gender justice 'argued that the home should not be excluded from the domain of justice but rather be recognised as a site within which the demands of justice held sway' (Jaggar 2009a: 6). Secondly, feminists have expanded philosophers' conception of what can be objects of justice, when they argue that also responsibilities for caretaking and other types of unpaid work must be considered from the perspective of distributive justice.

Jaggar then moves over to the question of what political philosophers have had to say about global justice. Also these philosophers have challenged conventional answers to the question of the proper domain of justice, when they have argued for including 'the international sphere' along with 'the national spheres' in justice considerations (Jaggar 2009a: 8). In addition, theories of global justice add a new category of subjects entitled to make justice claims, namely states (Jaggar 2009a: 7).

Jaggar regards these challenges from the perspective of global justice, along with the challenges raised from the perspective of gender justice, as important separate challenges to theorising on justice. However, there is also a need to link the two perspectives, and here, Jaggar sees an unfortunate lacuna in the literature: So far, few theorists have tried to think systematically through how to most properly connect feminist and global justice concerns. A main reason for this, Jaggar argues, is that the global justice debate so far has been construed as a debate between 'cosmopolitanism' and 'nationalism' and therefore circled around the question of 'the moral salience of state boundaries' (Jaggar 2009a: 8). Yet, from the perspective of global gender justice, what is crucial, rather, is to trace 'the ways in which contemporary transnational institutions and recent global policies, most of them facially gender-neutral, have had systematically disparate and often burdensome consequences for specific groups of women in both the global North and the global South' (Jaggar 2009a: 9). On this presumption, Jaggar has in different contributions analysed global gender injustice in terms of 'transnational cycles of 
gendered vulnerability' (Jaggar 2009b, Jaggar 2013, Jaggar 2014). 'Global gender disparities' should be considered as caused by 'a network of norms, practices, policies, and institutions that include transnational as well as national elements', factors that sometimes 'modify' or even 'reduce' one another, but that most often 'maintain' or 'intensify' one another, constituting powerful 'causal feedback loops' (Jaggar 2009b: 33).

Importantly, analysing such global gender vulnerabilities adequately requires further revision of the answers to both the where, who, and what-questions of distributive justice. Also when global justice is at stake, the domain of justice must include households and families, while the object of justice must include unpaid caretaking contributions and responsibilities, along with standard feminist prescriptions. However, in addition, it must systematically be considered how all these aspects of gender justice are affected by global networks and feedback loops (Jaggar 2009a: 12). Furthermore, theorising on the basis of global gender justice includes yet another subject of justice, namely 'gendered transnational collectivities' that along with individuals, other groups, and units such as states, should be granted the authority to raise justice claims worthy of moral consideration (Jaggar 2009a: 2, 12).

\section{Nancy Fraser: Global Gender Justice as Participatory Parity}

In her approach, Nancy Fraser (2013: 164) defines a just society as a society that ensures parity in participation for all. A gender just society, accordingly, is a society freed from 'sexism', today a key obstacle to the fulfilment of participatory parity in that it impedes 'gender parity' (Fraser 2013: 162, 169). To achieve a sexism-free society characterised by gender justice requires, moreover, that we view 'gender bifocally - simultaneously through two different lenses', as 'a categorical axis that spans two dimensions of social ordering', distribution and recognition. From the distributive perspective, gender appears as 'a class-like differentiation, rooted in the economic structure of society', and as 'a basic organizing principle of the division of labour', where women are assigned primary responsibility for unpaid, domestic labour, and for 'lower-paid, female-dominated 'pink collar' and domestic service occupations' (Fraser 2013: 162). From the perspective of recognition, gender functions rather as 'a status differentiation' coding 'persuasive cultural patterns of interpretation and evaluation' (Fraser 2013: 162). Fraser exemplifies with the cultural code of 'androcentrism: an institutionalised pattern of cultural value that privileges traits associated with masculinity, while devaluing everything coded as "feminine", and that structures social interactions in everything from law, policy and professional practice, to popular culture and everyday interaction (Fraser 2013: 162).

Accordingly, to combat gender injustice requires both 'a politics of redistribution' and 'a politics of recognition', and what Fraser (2013: 164) refers to as 'a two-dimensional conception of justice', which takes into account how sexist injustice is the combined result of women's subordination both as class and as status group. On the one hand, for participatory parity to be possible, the distribution of material resources must be such 
that it ensures 'participants' independence and "voice" - 'the objective condition' for justice must be satisfied. On the other hand, 'institutionalised patterns of cultural value' must 'express equal respect for all participants and ensure equal opportunity for achieving social esteem' - to satisfy 'the intersubjective condition' of justice (Fraser 2013: 164). Moreover, to ensure the satisfaction of these two conditions, Fraser (see Fraser \& Honneth 2004, but also Fraser 2013: 204-206) argues for 'transformative' policies (above 'affirmative' policies), or if 'transformative' policies are hard to identify or implement, 'affirmative' policies with transformative long-term effects ('non-reformist reforms'). In other words, she believes we should prefer policies that target the causes of gender-specific maldistribution and misrecognition, to policies that aim at correcting unequal end-state patterns, or, as a second best option, end-state correcting policies that are likely to affect the causal mechanisms producing and re-producing class hierarchies and status inequalities in the long run.

However, more precisely when we should regard the objective and the intersubjective conditions of participatory parity satisfied, and what detailed policies we should pursue to ensure it, is in the end not something for the justice theorist to monologically decide. 'The Platonic stance' in political philosophy - the philosopher's top-down theorising on what justice requires - must be complemented by a dialogical 'Aristotelian stance' that recognises citizens' different reasonable views and the role of democratic deliberations in justice assessments (Fraser and Honneth 2004: 206-207). ${ }^{3}$ There is thus, in addition to the economic and cultural dimensions of justice and participatory parity's objective and intersubjective condition, also a 'political' dimension or condition of justice; a 'stage' where democratic 'struggles', 'public contestation and deliberation' on both distributive and recognition issues are played out (Fraser 2013: 170, 195). Hence, in the end, justice is 'three-dimensional' (Fraser 2013: 193).

Yet, also the political 'stage' can be more or less conducive to participatory parity: Impeding such parity, can be lack of proper redistribution and misrecognition, but the problem can also be lack of proper 'representation' (Fraser 2013: 195). With 'representation', Fraser refers, for one thing, to the fairness of decision-rules: 'the procedures for staging and resolving contest', and for mooting and adjudicating claims in both 'the economic and the cultural dimensions'. How far '(d)o the (political) community's decision rules accord equal voice in public deliberations and fair representation in public decision-making?' (Fraser 2013: 195). Fraser emphasises here the persistent problem of institutionalising decision-procedures that ensure women a voice and influence on par with men (Fraser 2013: 166, 196). She also emphasises, again, how it is not up to 'philosopher kings' to define the more detailed procedures and adequate policies (Fraser and Honneth 2004: 206), for example when 'gender quotas' are defensible or required (Fraser 2013: 196), but up to citizens in democratic deliberations.

\footnotetext{
3 '(...) the Platonic stance overlooks "the fact of pluralism"; neglecting the plurality of reasonable perspectives on how best to interpret the requirements of justice, it substitutes an inadequate monological decision-procedure for dialogical deliberation' (Fraser and Honneth 2004: 207).
} 
However, 'representation' refers not only to 'ordinary-political' decision-rule issues and controversies concerning the qualities of the procedures through which members of a political community make decisions. It also refers to the 'meta-political' question of who should be counted as members of this community in the first place: '(W)ho is included in, and who excluded from, the circle of those entitled to a just distribution', 'reciprocal recognition', and fair decision rules (Fraser 2013: 195, 196, 206)? This is what Fraser refers to as the issue of 'framing' and 'misframing', which is 'when the community's boundaries are drawn in such a way as to wrongly exclude some people from the chance to participate at all in its authorised contests over justice' (Fraser 2013: 197).

It is not least 'globalisation' that has contributed to making the misframing problem visible (2013: 197). Globalisation has, on the one hand, made the economic and cultural structures that cause maldistribution and misrecognition increasingly transnational. Neither the gendered division of labour nor gendered symbolic patterns and evaluative schemes can be properly understood and explained without an eye to cross-border economic and cultural processes and mechanisms. On the other hand, globalisation has caused us to re-examine 'the assumption that the appropriate unit of justice (is) the territorial state' (Fraser 2013: 197). This conventional 'Keynesian-Westphalian frame' is insufficient in a world where class hierarchies and status inequalities stretch across states, many people lack state citizenship, social movements mobilise transnationally, and international organisations take on supranational features (Fraser 2013: 189-208). Furthermore, these issues must be analysed with gender in mind: The effects of migration and citizenship regulations are gendered, the women's movement has become increasingly transnational, and contemporary global and regional institutions, from the World Bank to the UN and the EU, tend to promote 'neoliberal' policies of development with deeply gendered consequences (Fraser 2013: 209-226). For Fraser, maldistribution, misrecognition and misrepresentation - in the ordinary-political sense, and when it occurs as misframing - are thus essentially intertwined problems of gender and global injustice. Finally, there is, in her approach, no justice without democracy. The detailed parameters and policies to ensure participatory parity must be defined by all affected in democratic processes - including when the issue is framing. The justice theorist can highlight the limitation of the 'Keyenesian-Westphalian frame', but must in the end leave the meta-political question of adequate alternative frames, and of how to most properly institutionalise this or the other frame, to (meta-)democratic deliberation and contestation.

\section{An Initial Comparison}

Across Jaggar's and Fraser's different vocabularies and conceptualisations, we should first of all recognise their substantive agreement in fundamental respects. With her analysis of the gendered division of labour and the effects of androcentrism across social spheres, Fraser would most likely have few problems with subscribing to Jaggar's elaboration of how feminist interventions have changed our ideas of the proper domain and objects of justice assessments to include also family life and intimate relations, care 
responsibilities and unpaid work. Both theorists also firmly agree that globalisation has brought to the fore a new domain of justice - 'the international sphere', to use Jaggar's term - and that 'the Keynesian-Westphalian frame', to use Fraser's term, is insufficient if we want to properly address the new challenges of global justice spurred by the occurrence and expansion of this 'sphere'. Finally, the way Jaggar elaborates on how issues of global and gender justice intersect and continually interfere with one another, and create global chains of 'gendered vulnerability', parallels Fraser's analyses of how gendered economic and cultural structures, class hierarchies and status inequalities, arise and re-produce across state borders. Both highlight also how justice considerations that aim to take both global and gendered concerns properly into account, must conceptualise and address the claims coming from the increasingly globalised 'women's movement' (Fraser) and 'gendered transnational collectivities' (Jaggar).

At the same time, the two theorists' approaches are distinctive and different - although in maybe somewhat unexpected ways. Initially, Fraser's justice theory seems to be broader and include more issues. Where Jaggar seemingly reduces all questions of justice to questions of 'distribution', Fraser emphasises that satisfying 'the objective condition' - redistributing material resources - is not enough to guarantee justice. Participatory parity also requires fulfilment of the 'intersubjective' and 'political' conditions: institutionalised evaluative patterns that ensure status equality, and procedures and framings conducive to fair and equal representation.

However, a closer look at what Jaggar includes as questions of distributive justice makes it clear that her approach is more wide-ranging than it seems, and that she and Fraser have different understandings of what a preoccupation with issues of distributive justice implies. For one thing, Jaggar also highlights how groups, be it ethnic minorities or women, and not only individuals, can be subjects of justice, and how the objects they make justice claims over, can be cultural recognition, and not only material resources. Jaggar in one passage even subscribes to Iris Marion Young's 'relational approach to justice', and her critique of political philosophy's focus on the allocation of goods and positions, and so on 'the outcomes of social processes' at the expense of 'the character of the processes and procedures that generate those outcomes' (Jaggar 2013: 117). This signals a preference for transformative over affirmative policies similar to Fraser's. Hence, both Jaggar and Fraser regard misrecognition as a fundamental justice concern, and maldistribution as a problem that calls for strategies and policies that target its root causes. However, whereas Jaggar conceptualises these insights in terms of revised and expanded answers to her listed questions of distributive justice, Fraser sides with those theorists who have argued that misrecognition and transformative policy approaches cannot be properly conceptualised and addressed within 'the distributive paradigm' (see Young 1990 for the classical formulation). Instead of assessing the extent to which the 'distribution of the benefits and burdens of participating in a cooperative enterprise' is fair (Jaggar 2009a: 2), we need a new justice paradigm where we rather assess whether 'social arrangements' more generally are conducive to participatory parity (Fraser 2013: 193). 
With regard to the two theorists' seemingly different treatment of what Fraser refers to as 'the political condition' of justice we can observe something similar. Once more, consulting Jaggar's list (2009a: 2) reminds us that the how-question asking 'which principles (that) are the most morally appropriate for guiding the allocation of various objects to various subjects in various circumstances', is one of several questions of distributive justice. Jaggar's approach to distributive justice is thus compatible with putting key weight on the procedural question and democratic principles: In Jaggar's vocabulary, Fraser's view that just patterns and policies of distribution and recognition is to be settled in processes of democratic deliberation characterised by adequate decision procedures and framings, is her answer to the question of 'which principles that are most morally appropriate' for allocating justice. However, in contrast to Fraser, Jaggar does not specify democracy as an ultimate how-principle. To be sure, 'participation' - or 'participating in a cooperative enterprise' - is in the end what just allocations should be good for even according to Jaggar (2009a: 2). Jaggar (2009a: 4-6) also firmly recognises unfair allocations of decision-making positions as a case of distributive injustice, and as far as these allocations are to women's systematic disadvantage, a case of distributive gender injustice. Yet, there seems to be no parallel in her approach to Fraser's 'Aristotelian stance', which claims that democratic principles of fair and equal representation should have the priority above other procedural and other principles in justice assessments, and accordingly, no explicit commitment to prioritise democracy in this sense in considerations on what global gender justice requires, even if gendersensitive democratisation is clearly a central aspect of Jaggar's idea of what a gender just world order implies.

\section{Jaggar, Fraser and the GLOBUS Framework}

Having noted these initial similarities - and differences - between Jaggar and Fraser, this section will go on to further compare and assess the two theorists' positions in light of the GLOBUS approach to global political justice. How can Jaggar's and Fraser's positions be conceptualised in GLOBUS terms, and what are the limitations of their positions from a GLOBUS perspective?

\section{GLOBUS: A Framework and Three Conceptions of Global Political Justice}

The GLOBUS perspective refers here to the GLOBUS research project and the way this project outlines a distinctive approach to global justice, and a set of global justice conceptions based on this approach (Eriksen 2016; Sjursen 2017). It should be noted, first, that this approach is global in scope; justice is not primarily assessed as a virtue of polities, be they states or regional powers such as the EU, but as a virtue of the international system or the global order at large. Gender justice is however not a specific concern of the GLOBUS approach. Still, general ideas of global justice of the kind 
GLOBUS presents can be specified and operationalised so they are relevant for gender justice assessments (Borgen 2018, Holst 2018). Furthermore, feminist theorists - and as will become clear Nancy Fraser's justice theory in particular - are included in GLOBUS' discussions of what justice is fundamentally about. We will return to both these aspects of the relationship between GLOBUS and global gender justice discussions in the concluding section. Secondly, the declared focus of GLOBUS is on 'global political justice', i.e. less on redistributive issues and the 'fair share' of 'goods', and more on the more or less 'just' qualities of 'political and administrative structures that could alleviate or even out harsh material conditions and ensure the protection of basic rights' (Eriksen 2016: 1, 3). Thirdly, it is not assumed to be one overarching principle or set of principles of global political justice written in stone, but instead multiple and not necessarily mutually exclusive 'reasonable conceptions of justice which highlight important concerns and dilemmas', but that may come with 'serious limitations with regard to the requirements of justice at the global level' (Eriksen 2016: 4). The implication is that particular contributions to justice theorising may rely on different conceptions at the same time, and that 'limitations' of this or the other contribution will depend decisively on which conception is granted priority, and on how the different conceptions, if there are more, are theorised and brought in relation to one another.

More specifically, GLOBUS elaborates on three conceptions of global political justice (Sjursen 2017: 4-9). First, there is global justice as non-domination. This conception regards the freedom of individuals as primarily protected within the state structure. International law and human rights are central for regulating global interaction, according to this conception, but involvement in multilateral institutions must take place on a voluntary basis, and states must recognise each other as equal and refrain from interfering in the affairs of other states. However, a severe limitation of global justice as non-domination is the risk of inefficiency: 'Justice as non-domination has limited capacity to eliminate dominance globally, as there is no duty of justice beyond borders that can be legally enforced' (Eriksen 2016: 12). Arguably, to prevent current 'global problems' and solve international collective action problems, stronger 'institutional provisions' than the non-domination conception allows for is needed (Eriksen 2016: 12, 13).

The second conception, global justice as impartiality, regards instead the autonomy of individuals as a universal normative concern across political and cultural contexts, and states as having relative value depending on the extent to which they ensure and enhance individual rights. Interference in the internal affairs of states may thus be required when the freedoms of individuals are at stake. Accordingly, this global justice conception prescribes the establishment of effective legal instruments and supranational institutions beyond the state. The challenges of this conception is in part potentially limited feasibility - what are the chances of establishing this kind of world order? - and in part the danger of world-state 'authoritarianism' were this order in fact to be established (Eriksen 2016: 17, 18). In addition, there is 'the democratic objection': 
who is the legislator - the citizens as a whole, the judges, or the international lawyers? The problem here is that justice as impartiality depends on the integrity of the complete interpreter, the (fictional) Judge Hercules who relies 'upon his own convictions in matters of morality'. Such a judge supposedly has a complete overview of all the valued principles and policies necessary for justification, as well as handle on the complex set of arguments underpinning the far-flung elements of existing law. Here, we find the ideal of the judge who proceeds monologically and is distinguished by virtue and privileged access to the truth: Judge Hercules takes it upon himself to arbitrate in the name of all

(Eriksen 2016: 17)

Finally, global justice as mutual recognition shifts the focus from blueprint solutions for all to mechanisms that recognise difference. Actors are different; contexts are different; experiences are particular, and vary; and there exists a plurality of values and worldviews. In this situation, global justice as mutual recognition requires that all perspectives are given due hearing. Only in this way, this justice conception contends, can we know what justice properly means and requires, and develop solutions that are adequately sensitive and relevant in a variety of contexts and among differently equipped and situated actor groups. It is noted how 'this account of justice may fare better than the previous accounts on some scores' (Eriksen 2016: 21) - it addresses the democratic problem and eases worries over world-state authoritarianism. Still, this conception is limited to the extent that it ends up prioritising groups' rights to 'a culture' above individuals' right of equal concern and respect. It also tends to underestimate 'the need for strong institutions to eliminate dominance'. It can be hard to ensure due hearing for all 'without enforceable rights and ensure justice without the sanctioning of non-compliance' (Eriksen 2016: 22).

\section{How do Fraser's and Jaggar's Theories Fare in a GLOBUS Perspective?}

These three justice conceptions prevail in different ways and to a different extent in the contributions of the two feminist theorists under discussion. This shapes the assessment of the contributions' limitations from a GLOBUS perspective. However, first, a central similarity should be noted: The conception of global justice as non-domination, while not absent, plays a limited role in both Jaggar's and Fraser's theories. Fraser emphasises explicitly how most feminists, despite their 'anti-etatism' and wish to move beyond rigid 'Westphalianism', never rejected 'state institutions simpliciter': 'The goal (...) was less to dismantle state institutions than to transform them into agencies that would promote, and indeed express, gender justice' (Fraser 2013: 216), and 'to supplement the stateterritorial principle of the Westphalian order with one or more post-Westphalian principles' (Fraser 2013: 202). The result is a pragmatic multi-level approach to the framing of political communities that ranks 'social efficiency' above any principled commitment to either 'state territoriality' or 'anti-Westphalianism' (Fraser 2013: 200- 
206). Jaggar (2009a: 8) signals a similar approach with her critique of how the debate between 'communitarians' and 'cosmopolitans' has distorted attention away from the more fundamental issue of how to more effectively address gendered vulnerabilities and injustices in a world characterised by new and more complex interactions between local, national and global spheres. None of the two theorists commit, then, to the strong defence of state sovereignty characteristic of the non-domination conception of global justice, even if they both consider state structures and state-level reform as vital for protecting women's rights and gender justice. Accordingly, when the GLOBUS framework highlights how a rigid justice as non-domination position stands the risk of becoming ineffective in light of all the known collective problems that transcend state borders, this does not apply strongly to our selected feminist justice theorists. They are both well aware of the limitations of the state territoriality principle and the need for other framing principles and institution building between and above states when justice requires it.

However, when seen in relation to the GLOBUS global justice conceptions of impartiality and mutual recognition, the differences between Jaggar's and Fraser's positions are brought to the fore, and Jaggar's approach inevitably comes out as more 'limited' than Fraser's. Initially, Jaggar, along with Fraser, subscribes to decisive elements of the impartiality conception: the idea of individual rights to justice irrespective of state citizenship, and the need to ensure these rights through supranational institutions and law enforcement when needed. Moreover, since this conception is tempered by an understanding of the potential importance of state structures - in accordance with the non-dominance conception of global justice - the charge against impartiality promoters of world-state authoritarianism and limited feasibility applies only to a limited extent, if at all.

Yet, in contrast to Fraser, Jaggar does not explicitly commit to the 'Aristotelian stance' approach of linking justice assessments and policy-making based on such assessments to inclusive democratic deliberation and public contestation. Accordingly, even if Jaggar allows for groups as subjects of justice, in accordance with the mutual recognition conception, and includes cultural recognition as an object of justice - although conceptualised as a 'distributive' good - her position does not include this conception's priority of democratic procedures. In a GLOBUS perspective, this limits the value of her contribution to justice discussions: Jaggar becomes guilty of the 'philosopher king' (Fraser) or 'Judge Hercules' (Eriksen) charge. Fraser comes in comparison close to the GLOBUS approach with her emphasis on 'the political condition' of justice assessments and just policy-making: The politics of redistribution and recognition should, she says, be based on democratic procedures with equal and fair representation. Moreover, with her preference for transformative policies above affirmative - which results in an explicit critique of the role of 'identity politics' in contemporary recognition struggles (Fraser 2013: 167-170) - Fraser does not stand out as a theorist that unreflectively prioritises group rights above individual rights. Furthermore, her commitment to global justice as impartiality makes her sensitive to the significance of 'strong institutions' at the global level, when needed. 


\section{"Distribution" or "Participation"?}

However, it is important to bear in mind that this is not necessarily the final word about the merits and shortcomings of Jagger's and Fraser's respective positions. Their theories may have features that make GLOBUS parameters irrelevant or less relevant, and GLOBUS parameters can also be questioned. To be sure, some of the weaknesses of Jagger's views that the GLOBUS framework contributes to make us aware of, seem generally warranted. For one thing, it does seem inadequate - at least it is far from straightforward (see Young 1990, ch. 1) - to talk about cultural recognition, what Fraser refers to as 'the intersubjective condition' of justice, and policies that aim at transforming economic and cultural root causes, in distributive terms. With her concern for individuals' and groups' recognition and her call for policies that go beyond redistribution of end state patterns, Jaggar accepts in theory important elements in the critique of 'the distributive paradigm' (Jaggar 2013: 117). However, in the end, she sticks to this paradigm, without further elaboration.

Furthermore, even if we have shown that Jaggar's distributive justice notion allows her to raise the 'how-question' of which procedural and other principles that our justice assessments should be generated from, her approach on this point is limited in at least two ways. For one thing, it disregards how feminist justice theorists have contributed distinctively to revise answers also to the how-question, and not only to the where-, whoand what-questions of the proper domain, subjects and objects of justice. One example are the several feminist attempts to revise the early Rawls' contract-theoretical argument for 'justice as fairness'-principles. In A Theory of Justice (1971) Rawls rigs a hypothetical contract situation - 'the original position' - and argues that his fairness-principles would be the set of principles preferred by the contract parties. Feminists have however thoroughly criticised the male bias of this contract situation, for example when Rawls conceptualises the parties of the original position as 'head of households', or when he defines the 'basic structure' - the set of societal institutions where the selected justice principles are to be applied - excluding the family (for example Susan Moller Okin 1989, Martha Nussbaum 1999, 2006, Drucilla Cornell 1995, 1998). Another example are the range of feminist theorists who, like Fraser, takes an explicit democratic approach to justice theorising, and, also like Fraser, develops consciously gender-sensitive elaborations of the democratic procedures within which justice claims are to be deliberated upon. Consider for example feminist arguments for descriptive representation, and so, when needed, for gender quota policies (see Mansbridge 1999 for a paradigmatic treatment), and feminist arguments for expanding the notion of 'deliberation' to include 'speech-genres' that lie closer to women's communicative styles (see Young 1997 on replacing 'deliberative democracy' with 'communicative democracy'). Secondly, Jaggar's approach is unclear in that it, on the one hand, assumes justice-generating procedures with democratic credentials, for example when she argues for a prominent role of 'transnational gendered collectivities' in the promotion of global gender justice, while she, on the other hand, discusses justice questions, and raise the question of justice-generating procedures (her how-question of distributive justice) 
without giving any principled treatment of the democracy issue. On this point, Fraser's theorising fares better, and the GLOBUS framework reminds us of a central requirement to sound justice theorising: It should relate itself and take into account democratic commitments and reasonable interpretations of democracy norms.

Still, to be fair to Jaggar, we must also recognise, first, that the GLOBUS framework is explicitly biased towards questions of 'political and administrative' norms and organisation, whereas questions of 'distribution' and the 'fair share' of 'goods' are considered vital, but secondary, given GLOBUS' research questions. A central aim for Jaggar is however exactly to account for feminist contributions to global gender justice discussions on different 'distributive' issues. This account may have merits and shortcomings, but if so, the GLOBUS framework with its 'political' focus is not rigged, and so not particularly equipped, to trace them. Secondly, we can hold it against Jaggar that she does not connect her justice theorising more explicitly to the general democratic requirements that her theorising at the same time seems to assume. Still, if we accept the fact of 'reasonable pluralism' - the point of departure of both Fraser (2004: 207) and GLOBUS (Eriksen 2016: 4) - i.e. the fact that persons may reasonably disagree on what normative principles mean and imply, we cannot assume that democracy principles are somehow exempted. Democratic theorists defend democracy ideas that are more or less 'aggregative' or 'deliberative', more or less 'participatory' or 'elite', and more or less based on arguments about 'good outcomes' or 'intrinsic value', and it seems unfounded to assume that these disputes are all unreasonable (Christensen and Holst 2017). Accordingly, we must allow for the possibility that approaches to justice that deviates from Fraser's (2013: 193) 'radical-democratic interpretation of the principle of equal moral worth' can be reasonable, for example approaches that are more critical of deliberative democracy (for example because they are more participatory or aggregative), have a stronger epistemic orientation, promote a different mixture of the Aristotelian and Platonic stances, etc. As for the GLOBUS framework it does not explicitly exclude this possibility, but the framework itself seemingly commit to an understanding of democracy close to Fraser's, for example when Fraser's idea of 'parity of participation' is held up tout court as a normative standard in global justice considerations (Eriksen 2016: 23). There seems thus to be a certain ambivalence in this framework between, on the one hand, its commitment to reasonable pluralism in defining 'global political justice', and, on the other, its promotion of more substantive and 'radical' ideas of democratic justice.

\section{Conclusion and Implications}

This paper has presented and compared two prominent approaches to global gender justice; Alison Jaggar's 'distributive' approach and Nancy Fraser's 'participatory' approach. We have found that the two theorists have contributed to developing the feminist criticism of the domains and objects of justice along similar lines. They both also recognise 'the international sphere' as a new domain of justice; emphasise the 
entanglement of global injustices and gender vulnerability; and identify new gendered political subjects in transnational movements. Yet, there are also considerable differences, in that Fraser makes an explicit break with 'the distributive paradigm' and puts the relationship between justice and democracy at the centre stage, whereas Jaggar formulates her justice notion in distributive terms, and leaves the more detailed relationship between justice and democracy largely unaddressed.

The two theories, their similarities and differences, have furthermore been discussed and assessed in light of the GLOBUS framework and its conceptions of global political justice. Here we found that justice as non-domination plays a non-trivial, yet limited, role in both theorists' approaches. Justice as impartiality also prevails in both contributions, but whereas impartiality ideas are tempered in Fraser by her democratic approach and commitment to the core ideas of the mutual recognition conception, Jaggar's theory stands out as more limited and with a democratic deficit, from a GLOBUS perspective.

Finally, we have argued that GLOBUS assists us in identifying what seems to weaker points in Jaggar's global gender justice approach; in particular, her less than convincingly accounted for reliance of distributive justice as the underlying core idea of justice, and her underdeveloped account of democratic 'how-principles' and the relationship between democracy and justice. At the same time, we should keep in mind GLOBUS' conscious focus on questions of political justice, and how this framework, due to its research purposes, thus sets aside several of the central distributive issues that Jaggar primarily wants to address with her global gender justice theorising. A criticism of a possible democratic deficit in Jaggar's approach should also distinguish between the promotion of 'radical-democratic' ideas of democracy of the kind Fraser pursues, which can be reasonably disputed, and a commitment to general democratic norms compatible with the fact of reasonable pluralism, and the need for justice theories that account for and relate to such norms.

From this paper's discussions and findings, some lessons for feminist theory can be drawn. Fraser and Jaggar both show through their theorising the importance of engaging with theories of justice from a feminist perspective, and with issues of global and gender justice and the ways these are intertwined. Approaching these concerns from different philosophical angels, there is still an interesting overlap in preoccupations between these two theorists when it comes to features of their societal analysis, their normative assessments and policy approach, and their conceptualisation of what feminist interventions in justice theory are fundamentally about. This gives the impression of a certain common ground that future feminist theorising on justice can take as its point of departure and progress from.

Still, Jaggar and Fraser also differ in some basic and instructive respects. Fraser raises a major democratic challenge to theorising on justice, which contemporary feminist theories of distributive justice need to relate to much more closely and take into account. The more detailed theoretical, normative and institutional implications for justice 
theorising of a democratic commitment are however up for reasonable discussion, and Fraser's intervention should hence be seen less as settling the issue of 'democracy', than as opening a new area of debate for feminists. It is also less than clear where Fraser's democratic approach to global gender justice leaves a range of ongoing 'Platonic stance' debates on distributive justice that engage feminist theorists along with many others.

The paper also sheds light on the more specific contribution from GLOBUS to discussions of global justice. First and foremost, we have showed the usefulness of GLOBUS' framework and justice conceptions for our comparative and evaluative endeavour: It turned out to be fruitful in a range of respects to analyse and assess two theories of global gender justice in light of GLOBUS' parameters and distinctions. Yet, GLOBUS' political focus makes this framework less suited for analysing and recognising the full value of contributions, such as Jaggar's, that concentrate more on distributive questions. The paper's investigations also made visible a need to elaborate further the relationship between, on the one hand, GLOBUS' commitment to reasonable pluralism and, on the other, this framework's seemingly rather substantive interpretation of what democracy implies.

Finally, discussions of global gender justice of the kind Jaggar and Fraser provide can be used to add gendered dimensions to GLOBUS. Fraser's analysis of gendered divisions of labour and the effects of androcentrism across social spheres; Jaggar's elaboration of how justice assessments must include also family and intimate relations, care responsibilities and unpaid work; and both theorists' emphasis on the importance of women's representation and gender-sensitive decision-making, can assist us in specifying feminist requirements to the different GLOBUS models. For the conception of global justice as non-domination to be a conception that is also one of global gender justice, it is crucial that state structures and policies address gendered problems of maldistribution and misrecognition as well as gendered vulnerabilities that occur in the family and intimate sphere, and that state level democracy includes women on par with men. Similarly, a conception of global justice as impartiality tailored towards feminist concerns must not only focus on the extent to which supranational institutions, individual rights-catalogues and international law are in place. It must also, and in particular, focus on whether these institutions and mechanisms are shaped properly and effectively to address gender injustices of the kind Jaggar, Fraser and other feminist theorists have made us aware of. Lastly, the conception of global justice as mutual recognition, with its focus on context-sensitive and democratically produced justice assessments and policies, must, to live up to feminist requirements, systematically consider the local shapes of gendered cultural and economic structures and divisions of labour, and how decision-making on all levels takes into account the plurality of views among both women and men. 


\section{References}

Borgen, Vera Sofie (2018): 'The EU as a Promoter of Gender Justice. Combating Trafficking in the Face of Migrant Crisis'. Paper presented at the GLOBUS workshop Gender and EU Foreign Policy, Dublin 29-30 November 2018.

Christensen, Johan and Cathrine Holst (2017): 'Advisory Commissions, Academic Expertise and Democratic Legitimacy: The Case of Norway', Science and Public Policy 44(6): 821-833.

Cornell, Drucilla (1995): The Imaginary Domain: Abortion, Pornography, and Sexual Harassment. New York, NY: Routledge.

Cornell, Drucilla (1998): At the Heart of Freedom: Feminism, Sex \& Equality. Princeton, NJ: Princeton University Press.

Eriksen, Erik Oddvar (2016): Three Conceptions of Global Political Justice, GLOBUS Research Paper 1/2016. Available at: https://papers.ssrn.com/sol3/papers.cfm? abstract id=2878745.

Fraser, Nancy and Axel Honneth (2004): Redistribution or Recognition? A Political Philosophical Exchange. New York, NY: Verso.

Fraser, Nancy (2013): Fortunes of Feminism. From State-Managed Capitalism to NeoLiberal Crisis. New York, NY: Verso.

Holst, Cathrine (2018): Promoting Global Justice When Backlash Strikes, GLOBUS Research Paper 7/2018. Available at: https://papers.ssrn.com/sol3/papers.cfm? abstract $\mathrm{id}=3184285$.

Jaggar, Alison (2009a): 'The Philosophical Challenges of Global Gender Justice', Philosophical Topics, 37(2): 1-15.

Jaggar, Alison (2009b): 'Transnational Cycles of Gendered Vulnerability', Philosophical Topics, 37(2): 33-52.

Jaggar, Alison (2013): 'Does Poverty Wear a Woman's Face? Some Moral Dimensions of a Transnational Feminist Research Project', Hypatia, 28(2): 240-256.

Jaggar, Alison (2014): “'Are My Hands Clean?” Responsibility for Global Gender Disparities', in Diana Meyers (ed.) Poverty, Agency, and Human Rights. New York, NY: Oxford University Press.

Mansbridge, Jane (1999): 'Should Blacks Represent Blacks and Women Represent Women? A Contingent "Yes"', The Journal of Politics, 61(3): 628-657.

Nussbaum, Martha (1999): Sex and Social Justice. New York, NY: Oxford University Press.

Nussbaum, Martha (2006): Frontiers of Justice: Disability, Nationality, Species Membership. Cambridge, MA: Harvard University Press. 
Okin, Susan Moller (1989): Justice, Gender, and the Family. New York, NY: Basic Books.

Rawls, John (1971): A Theory of Justice. Cambridge, MA: Harvard University Press.

Sjursen, Helene (2017): Global Justice and Foreign Policy: The Case of the European Union, GLOBUS Research Paper 2/2017. Available at: https://papers.ssrn.com /sol3/papers.cfm?abstract id=2990461.

Young, Iris Marion (1990): Justice and the Politics of Difference. Princeton, NJ: Princeton University Press.

Young, Iris Marion (1997): Intersecting Voices: Dilemmas of Gender, Political Philosophy, and Policy. Princeton, NJ: Princeton University Press. 
GLOBUS Research Papers

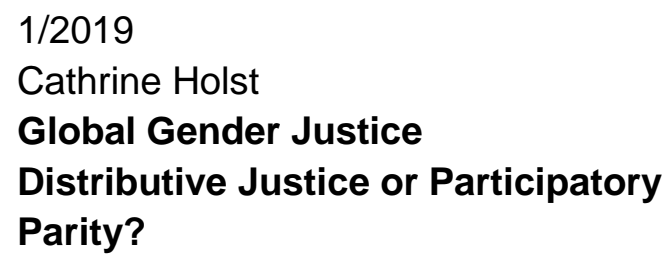

8/2018

Hayley Walker

Mutual Recognition in Global

Negotiations

The Case of the 2015 Paris Climate

Summit

$7 / 2018$

Cathrine Holst

Promoting Global Justice when

Backlash Strikes

EU and UN Beijing +20

6/2018

Espen D.H. Olsen

Out but Still In

Norway's Approach to Migration and Asylum as a non-EU State

$5 / 2018$

Samuel Brazys and Krishna C.

Vadlamannati

Aid Curse with Chinese

Characteristics?

Chinese Development Flows and

Economic Reform

$4 / 2018$

Michela Ceccorulli

On Protection and Justice

The Proposals for Reform of the

Common European Asylum System

$3 / 2018$

Ben Tonra

The (In)Justices of Peacekeeping

EUFOR Tchad/RCA

2/2018

Nikola Tomić and Ben Tonra

The Pursuit of Justice through EU

Security Strategies

Sisyphus Redux? 
$1 / 2018$

Alexa Zellentin

Different Angles on Climate Justice Insights from Non-domination and Mutual Recognition

$6 / 2017$

Mai'a K. Davis Cross

Europe's Foreign Policy and the Nature of Secrecy

$5 / 2017$

Bettina Ahrens

The Solidarisation of International

Society

The EU in the Global Climate Change

Regime

$4 / 2017$

Mai'a K. Davis Cross

EU Institutions and the Drive for Peace

The Power of Ideas
3/2017

Kjartan Koch Mikalsen

Equal Sovereignty

On the Conditions of Global Political Justice

2/2017

Helene Sjursen

Global Justice and Foreign Policy

The Case of the European Union

1/2017

Franziskus von Lucke

O Justice, Where Art Thou?

Developing a New Take on Climate

Justice

$1 / 2016$

Erik O. Eriksen

Three Conceptions of Global Political Justice 


\section{GLOBUS Research Papers}

The GLOBUS Research Papers are pre-print manuscripts on the EU's contribution to global justice as well as the wider question of Global Political Justice. The series is multidisciplinary, with a particular emphasis on the fields of international relations, political science, political theory, sociology and law.

\section{Reconsidering European Contributions to Global Justice - GLOBUS}

GLOBUS is a research project that critically examines the European Union's contribution to global justice. Challenges to global justice are multifaceted and what is just is contested. Combining normative and empirical research GLOBUS explores underlying political and structural obstacles to justice. Analyses of the EU's positions and policies are combined with in-depth studies of non-European perspectives on the practices of the EU. Particular attention is paid to the fields of migration, trade and development, cooperation and conflict, as well as climate change. GLOBUS' team of researchers covers the disciplines of politics, international relations, law, economics, sociology and political theory. The project is coordinated by ARENA Centre for European Studies at the University of Oslo and has partners in Brazil, China, Germany, India, Ireland, Italy and South Africa. It is funded by the Horizon 2020 Programme of the European Union for the period 1.6.2016 - 31.5.2020.

\section{Series Editor}

Helene Sjursen, ARENA Centre for European Studies, University of Oslo GLOBUS Coordinator

\section{Editorial Board}

Thomas Diez

Erik O. Eriksen

Sonia Lucarelli

Pundy Pillay

Ben Tonra
Institute of Political Science, University of Tübingen ARENA Centre for European Studies, University of Oslo Department of Political and Social Sciences, University of Bologna Wits School of Governance, University of Witwatersrand School of Politics and International Relations, University College Dublin 